\title{
PARA UMA CRITICA AO DISCURSO DA INOVAÇÃO: SABER E CONTROLE NO CAPITALISMO DO CONHECIMENTO
}

Isleide A. Fontenelle isleide.fontenelle@fgv.br

Professora da Escola de Administração de Empresas de São Paulo, Fundação Getulio Vargas - São Paulo - SP, Brasil

\section{INTRODUÇÃO}

Criatividade e inovação são palavras pronunciadas à exaustão no meio organizacional contemporâneo, a ponto de um estudioso da área concluir que as organizações ocidentais estão vivendo o fenômeno da neofilia, o culto ao novo (SIEVERS, 2007, p. 1). Segundo esse autor, como os meios tradicionais de transformação organizacional e de maximização do lucro têm se mostrado insuficientes ou falhado completamente, o capitalismo voltou-se para a ideia de que o velho é ruim, sendo o novo sempre melhor.

Constatação similar foi feita pelo sociólogo Osvaldo López-Ruiz, em sua pesquisa de doutorado, publicada em livro, sobre os executivos das transnacionais e $\mathrm{O}$ espírito do capitalismo. O autor concluiu que "um dos traços mais significativos do ethos" que tentou descrever "é a obsessão com o novo... Inovação, mudança, cria- tividade, empreendedorismo são hoje palavras de ordem dentro das grandes corporações e também, em boa medida, fora delas" (LÓPEZ-RUIZ, 2007, p. 70).

O tema da mudança tem uma longa história na prática e na literatura organizacional, portanto não se trata de um debate novo no campo. Qual seria, então, a especificidade desse contexto ao qual Sievers e López-Ruiz se referem como permeado pelo discurso do novo? Termos como criatividade e inovação parecem mobilizar outra ordem de sentido: enquanto o debate em torno da mudança nos remetia a um momento específico de transformação organizacional, a um acontecimento com data marcada, suportado por um projeto cuja implantação focava um resultado final, criatividade e inovação, ao contrário, são categorias que estão no núcleo do processo produtivo e organizacional contemporâneo, remetendo à ideia

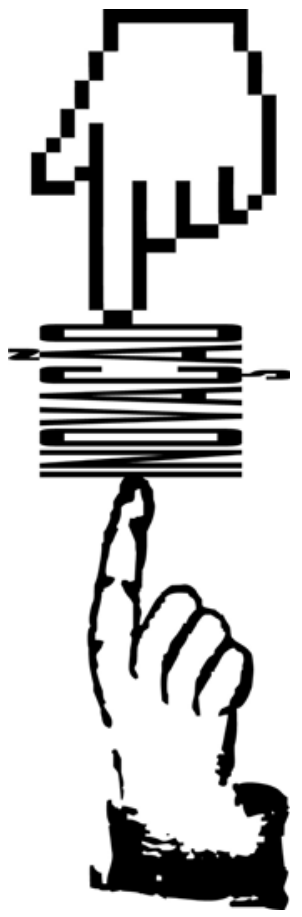

de mudança como algo constante e permanente.

De modo similar, o universo acadêmico também tem sido permeado pelo discurso da inovação permanente. Em seu livro Knowing Capitalism, Nigel Thrift (2005), baseando-se em estudos destacados sobre esse assunto, nos mostra como tem havido uma crescente simetria entre o mundo da academia - pensada no sentido grego das diversas instituições voltadas para o ensino artístico, literário, filosófico, científico - e o dos negócios, em especial na maneira como as duas instituições estão compartilhando as mesmas inquietações relacionadas à necessidade de inovar, transformando saberes em conhecimento. Essa tem sido, segundo Thrift, uma das características centrais e muito específicas desse novo estágio do capitalismo do conhecimento: os negócios têm se tornado cada vez mais acadêmicos, assim como a academia tem 
se tornado cada vez mais orientada pelos negócios. Assim, ao mesmo tempo que as disciplinas acadêmicas são absorvidas pelo mercado, tornando o capitalismo mais inteligente, fazendo uso de uma força de trabalho altamente qualificada, o aparato discursivo promovido pelas escolas de negócios, segundo Thrift, legitima tal estado de coisas, impondo ao mundo acadêmico uma forma de conhecimento à sua imagem e semelhança, ou seja, uma forma de produção de conhecimento rápida, capaz de atender à sua demanda por uma natureza prática do saber. Não por acaso, "o estudo acadêmico dos negócios cada vez mais enfatiza a importância da informação e do conhecimento, incluindo a possibilidade da inovação a partir do aprender-fazendo, cuja lógica está no aproveitamento do potencial do conhecimento que está incorporado nos sujeitos" (THRIFT, 2005, p. 22).

Diante desse quadro, tenho duas interrogações que procurarei responder ao final deste ensaio: a primeira é entender por que ocorreu essa inflação discursiva em torno dos conceitos de criatividade e inovação, sob a forma de um culto ao novo; a segunda é buscar entender como esse discurso está relacionado aos desafios que têm sido impostos ao contexto acadêmico em busca da inovação permanente (sistemas de métrica de produtividade, maior interlocução com as necessidades do mercado), bem como discutir os seus impactos.

Claro está que a inovação sempre foi fundamental para o processo produtivo capitalista, como veremos na primeira parte deste texto, mas qualquer leitor minimamente atualizado com a literatura de negócios há de concordar que o discurso em torno da inovação tem ganhado uma dimensão mais ampla e persistente nessas últimas décadas. Segue-se a isso minha segunda questão: entender a maneira como esse discurso se imbrica tão profundamente ao universo acadêmico e quais os seus impactos. Novamente é preciso marcar que não haveria novidade alguma em afirmar que a inovação também faz parte do contexto acadêmico, mas os que atuam nesse universo e escrevem sobre esse fenômeno - como veremos também ao longo deste ensaio - sabem muito bem que essa relação entre inovação e academia, permeada pelo que estou denominando aqui culto ao novo, remete a um novo contexto.

Conforme nos ensina o filósofo esloveno Slavoj Zizek, "o que é próprio do discurso humano é a lacuna irredutível entre o conteúdo enunciado e seu ato de enunciação... O ato de relatar publicamente uma coisa nunca é neutro; afeta o próprio conteúdo relatado..." (ZIZEK, 2006). Pretendo, portanto, desconstruir esse discurso em torno da importância do novo, entender suas razões. Relaciono esse discurso - que aparece sob a forma da inovação permanente - a um novo estágio do desenvolvimento capitalista que coloca o saber no centro do processo produtivo.

$\mathrm{Na}$ primeira parte deste texto, ao discutir o valor do novo, pretendo deixar claro como esse processo ocorreu e os desafios que ele coloca, hoje, para a própria sustentação desse modelo no contexto organizacional, assentado como está na "aceleração da aceleração" da inovação (FULLER, 1981).

$\mathrm{Na}$ segunda parte, ao tratar da mercantilização dos saberes, focarei no segundo objetivo deste ensaio, que é entender os impactos desse culto ao novo no universo acadêmico, que atinge em especial as escolas de negócios, mas não se esgota nelas.

Na parte final, proponho pensarmos o discurso da inovação como parte de um novo regime de dominação, denominado, pelo filósofo Gilles Deleuze, sociedades de controle.

\section{O VALOR DO NOVO}

O culto ao novo aparece frequentemente sob a forma do discurso em torno da importância da criatividade e inovação, termos que não pertencem exclusivamente à área da gestão. A criatividade, que vem do latim creare - criar, inventar -, é foco de atenção das Ciências Humanas e Sociais, em especial da Filosofia, da Psicologia, da Sociologia, bem como da Administração. A inovação também pode ser compreendida como o ato de criar, inventar ou renovar, fazer algo existente de maneira nova, diferente da usual. Aplicada no contexto organizacional, a inovação está atrelada à concepção de utilidade - é criatividade posta em prática - e, mais propriamente, significa criatividade posta a serviço do processo de criação de valor para as organizações.

A inovação sempre esteve no âmago do processo de desenvolvimento capitalista, conforme já apontado por seu maior teorizador, Joseph Schumpeter, na sua obra Teoria do Desenvolvimento Econômico, publicada originalmente em 1911 (SCHUMPETER, 1982). Nessa obra, Schumpeter também faz questão de diferenciar o papel da criatividade - ou invenção -- 
da inovação: enquanto a primeira é criação de ideias, a segunda é a que permite que tais ideias sejam postas em funcionamento. A inovação, portanto, foi a resposta encontrada por Schumpeter para o entendimento da força que transforma incessantemente o capitalismo. E tal capacidade de inovação era creditada a um agente muito especial: o empreendedor, ou o empresário, agente capaz de inovar, ou seja, de fazer de maneira nova coisas que já haviam sido feitas.

Assim, à primeira vista, parece que assistimos a um ressurgimento das ideias schumpeterianas com base na ênfase contemporânea em inovação e empreendedorismo. Entretanto, tais conceitos reaparecem em um cenário sócio-histórico diferente daquele analisado e idealizado por Schumpeter, em torno do espírito capitalista dos pequenos e médios empresários. Em que pese o fato de que a inovação continue sendo vital para o capitalismo contemporâneo, ela agora ocorre em outro nível: estamos diante de uma nova etapa do desenvolvimento capitalista, produto da terceira revolução tecnológica que transformou o trabalho do conhecimento na principal força produtiva. É somente com base nesse cenário que podemos compreender o real sentido das palavras criatividade e inovação no contexto organizacional contemporâneo e a sua consequência imediata, qual seja a gestão do conhecimento.

O culto ao novo levou a diferentes processos de transformação organizacional, como os processos de dowsinzing e reengenharia. Segundo Sievers (2007), a maneira pela qual os processos de reengenharia foram aceitos por um vasto número de empresas nos anos 1990 parece ser a encarnação des- se culto. Trata-se, sem dúvida, de uma de suas facetas. Entretanto, pretendo focar outro componente desse processo: a busca por meios de acesso e controle sobre o saber humano. Tal perspectiva pode ser abordada com base em duas frentes: focando o contexto interno das organizações, avaliando como isso tem desenvolvido uma forma de dominação soft (COURPASSON, 2000) sobre a força de trabalho, envolvendo modelos de gestão como o Balance Scorecard (BSC), entre outras técnicas de registro e monitoração; ou com base em uma perspectiva mais ampla, que extrapola o contexto organizacional, envolvendo as relações entre saber, conhecimento e valor. É nessa última frente que estou mais interessada, na medida em que é ela que se implica mais diretamente com a questão da inovação no contexto acadêmico.

Mas, para compreendermos essa relação mais profundamente, é preciso que fique claro o papel que a inovação ganha nesse novo estágio do capitalismo. André Gorz, centrando sua análise na revolução informacional e nos desafios que ela coloca para o capitalismo atual, lembra como, no seu início, tal revolução visava reduzir custos de produção. Tendo atingido esse objetivo, a fim de evitar a queda no preço das mercadorias, a próxima etapa foi incrementar qualidades imateriais a tais produtos a fim de que se pudesse extrair deles rendimentos simbólicos de monopólio, ou seja, um sobre preço mediante o caráter de antecipação ou exclusividade no oferecimento de produtos e serviços que pudessem destacar-se por seu design ou marca publicitária. A partir desse momento, a obsolescência programada passa a ter um papel central, e a inovação permanente começa a ganhar, então, a sua dimensão atual. Ou seja, não se trata, apenas, de produzir novidades em um ritmo cada vez mais frenético, mas, principalmente, "transformar a invenção em mercadoria, e pô-la no mercado como um produto de marca patenteada" (GORZ, 2005, p. 42). Entretanto, como Gorz salienta, o saber, em princípio, não está disponível para ser manipulado como mercadoria. E é esse, exatamente, o desafio do capitalismo nesse novo estágio: $\mathrm{O}$ pesado investimento em pesquisas privadas, focado em inovação e associado a grandes investimentos em comunicação publicitária, visa à produção de mercados exclusivos, buscando "conferir às mercadorias o valor incomparável, imensurável, particular e único de obras de arte..." (GORZ, 2005, p. 11), ou seja, formas de saber que levam a rendimentos exclusivos. Nesse ponto, Gorz lembra-nos como a chamada economia do conhecimento contém a própria negação da economia capitalista comercial, na medida em que a sua força produtiva central precisa lançar mão de algo, o saber, que "não é uma mercadoria qualquer, seu valor (monetário) é indeterminável e sem custos; sua propagação eleva sua fecundidade, sua privatização a reduz e contradiz sua essência". Daí por que o termo economia do conhecimento, tratado como a nova forma do capitalismo, mascara todo o seu potencial de negatividade (GORZ, 2005, p. 59).

Nigel Thrift também destaca, em sua análise sobre o capitalismo do conhecimento (THRIFT, 2005), que a inovação necessariamente envolve a geração e desenvolvimento de informação e conhecimento, mas que esse conheci- 
mento é altamente problemático, na medida em que envolve a dificuldade de pensá-lo com base em categorias mercadológicas, já que não há mercados competitivos para mercadorias que ainda não foram concebidas como tais, levando aos limites da apropriação privada algo que pode ser assimilado como um bem público. Daí por que, tendo o desenvolvimento produtivo gerado a inconsistência no âmago do próprio capitalismo, esse agora trabalha e joga com a incerteza e, ao fazê-lo, gera novos tipos de agregação e ordenação do mundo. E isso é possível mediante a produção de um poderoso aparato discursivo que Thrift denominou "circuito cultural do capitalismo", ou seja, a maneira como "o capitalismo passou a lançar mão de um aparato discursivo que, através da contínua produção de conhecimento proposicional e prescritivo, tem o poder de fazer suas teorias e descrições do mundo se tornarem efetivas na produção de novas máquinas e novos corpos" (THRIFT, 2005, p. 11). As escolas de negócios, os consultores e gurus do mundo da gestão tiveram e têm, segundo o autor, uma importância central na moldagem desse mundo.

Segundo Thrift, para entendermos a lógica desse tipo novo de capitalismo - que está constantemente em movimento, que incorpora o saber e a inovação cada vez mais rapidamente e é mais adaptável que os modelos anteriores - é necessário entendermos como a chamada revolução da informação foi combinada a três novos desenvolvimentos capitalistas:

- novas formas de produção de mercadoria, envolvendo a produção para o consumo, bem como a valorização das marcas, patentes e finanças;

- novas formas de tempo e espaço de produção, com o desenvolvimento do conhecimento lógico posto a serviço de novos arranjos espaciais com redução de estoques, uma engenharia de produção e consumo mais rápida, monitoramento contínuo, enfim, formas de gestão do conhecimento, portanto, de controle); e

- novo tipo de discurso, ao qual o autor chama de circuito cultural do capitalismo que permitiu, inclusive, um maior compartilhamento linguístico entre academia e mundo dos negócios com o uso da palavra cultura.

Sobre esse último, a virada cultural na teoria social sob a ótica de teorias pós-modernas (EAGLETON, 2005) coincidiu com o circuito cultural do capitalismo posto em prática a partir dos anos 1990, que passou a enfatizar a imbricação entre economia e cultura, como as análises de Fredric Jameson (1996) sobre o pós-modernismo como lógica cultural do capitalismo tardio podem confirmar.

Tal aparato discursivo revela uma nova matriz de inteligibilidade com base na qual o processo de invenção é avaliado e regulado. Em que pese a importância desse discurso na propagação e sustentação dessa lógica, o que se pode afirmar é que, da perspectiva real de seu funcionamento, ela tem colocado desafios novos e constantes às empresas que, já não conseguindo suportar o processo acelerado e intermitente de gerar, nos seus limites internos, a próxima grande ideia que possa ser incorporada como mercado- ria, deslocam-se para o universo acadêmico, a fim de extrair desse um saber que converta a inovação para o mercado.

\section{A MERCANTILIZAÇÃO DOS SABERES}

Apresento, a seguir, uma reflexão sobre o estatuto do saber e do conhecimento científico quando, nas palavras de Hermínio Martins (2005), a sua capitalização se torna o aspecto determinante do capitalismo contemporâneo.

Em sua pesquisa sobre as implicações da informacionalização e da empresarização dos saberes, Maria Cecilia Diaz-Isenrath (2008) mergulha na análise da constelação eletrônico-digital-informacional para afirmar que "não há área do conhecimento na qual a 'informação' não tenha passado a afetar significativamente as práticas de pesquisa". "O que está assim em questão é menos a chamada economia da informação ou a sociedade do conhecimento como uma realidade socioeconômica dada, e mais o tipo de problema que o mainstream da economia, das teorias da administração e a análise de sistemas colocam, e os objetos e sujeitos sobre os quais esses saberem 'dizem', gerenciam, intervêm. O que acontece quando a produção de sentido é tratada como "produção' no sentido econômico, quando passa a ser objeto de 'gestão'?" (DIAZ-ISENRATH, 2008, p. 80).

Com base nas análises de uma ferramenta de busca na web, de um congresso e seus materiais sobre gestão do conhecimento, e de protocolos de rede e de banco de dados de uma agência pública de financiamento à pesquisa, e sob a 
perspectiva metodológica de que "Os discursos sobre as tecnologias fazem parte das tecnologias", a autora nos mostra com riqueza de detalhes como, sob um novo tipo de racionalidade política e econômica fundada no neoliberalismo, os chamados sistemas de informação "transformam as práticas de conhecimento e a produção de valor" (DIAZ-ISENRATH, 2008, p. 9).

É nesse contexto, seguindo a autora, que nos deparamos com a influência dessas chamadas ciências cinzas na produção e gerenciamento das condições de incerteza do capitalismo informacional. Daí por que "os redutos das diferentes profissões passaram a ser atravessados por técnicas destinadas a exercer um controle da autoridade, notadamente, as técnicas orçamentárias, de contabilidade e auditoria" (DIAZ-ISENRATH, 2008, p. 23). Trata-se de novos modos de controle: "o cálculo, o monitoramento, a avaliação e a gestão podem aparecer ao mesmo tempo como modestos e oniscientes, limitados e aparentemente sem limites, quando aplicados a problemas tão diversos como a conveniência de um procedimento médico ou a viabilidade de um departamento universitário" (ROSE, 1996, p. 54, grifo nosso).

Estamos, portanto, de volta ao debate do controle sobre o trabalho do conhecimento, dessa vez, no interior da própria academia. Aqui, a questão do controle também se coloca duplamente, como ocorre no contexto das organizações empresariais: de um lado, com base na implantação de meios de auditoria e avaliação acadêmicos, tais como relatórios, escores, ranking, benchmarkings; de outro, no sentido mais amplo da capitalização do conhecimento acadêmico-científico para fins comerciais.
Nesse aspecto, a análise efetuada por Diaz-Isenrath sobre o processo de criação do Google objetivando, segundo a autora, uma forma de "abordar, a partir de uma perspectiva micropolítica, as implicações dos processos de digitalização de conhecimento" (DIAZ-ISENRATH, 2008, p. 37), é exemplar. Contrapondo um artigo acadêmico escrito em 1998 por dois doutorandos em engenharia em computação, da Universidade de Stanford - Lawrence Page e Serge Brin, fundadores da Google -, ao pedido de registro da empresa por eles criada à Comissão de Valores e Bolsas dos Estados Unidos, em 2004, a autora demonstra de que maneira o conhecimento científico foi sendo apropriado pela lógica da empresa.

Com base em uma longa descrição do artigo escrito pelos ainda estudantes, Diaz-Isenrath mostra que Page e Brin narram como se deu o completo envolvimento de colegas, cientistas e técnicos do campo acadêmico no desenvolvimento do projeto, ao mesmo tempo que afirmam como seu artigo seria uma primeira descrição pública da criação desse tipo de ferramenta, qual seja uma ferramenta de busca. Quando entra em cena o pedido de registro, seis anos depois, o documento "dirige-se aos investidores. Essa descrição, que se publica em 2004 (a empresa passava a ser nesse momento uma companhia aberta), não diz respeito à 'anatomia do sistema' ou ao algoritmo, mas à 'missão da empresa', ao 'modelo de negócio' e ao 'plano de ação'" (DIAZ-ISENRATH, 2008, p. 52).

Enquanto no artigo de 1998 Page e Brin justificavam que projetaram tal sistema de busca a fim de auxiliar outros colegas pesqui- sadores e estudantes para "entrar rapidamente, processar grandes porções da web e produzir resultados ou experimentos interessantes" (BRIN e PAGE, 1998, p. 109), o pedido de registro, apenas seis anos depois, deixa claro que "a busca e a experimentação não se restringem à 'pesquisa' em sentido estrito" (DIAZ-ISENRATH, 2008, p. 52). Os fatores de risco envolvidos na relação entre estrutura corporativa e sistema técnico são também exaustivamente descritos no documento em questão.

A filósofa brasileira Marilena Chauí (2003), em interlocução com o trabalho de Michel Freitag (1996), ajuda-nos a compreender a lógica mais ampla dessa aplicação da racionalidade empresarial ao campo acadêmico. Partindo da concepção de universidade como uma instituição social - que aspira à universalidade, com legitimidade social e política e autonomia do saber perante o Estado, a religião e o mercado - a autora se pergunta como a universidade passou a ser uma organização social que, por sua vez, é "balizada pelas ideias de eficácia e sucesso... regida pelas ideias de gestão, planejamento, previsão, controle e êxito" (CHAUÍ, 2003, p. 6).

Chauí busca as explicações estruturais para essa mudança na própria transformação da ciência a partir da década de 1940, devido às mudanças tecnológicas e no modo de produção capitalista. Foi a partir desse período que a ciência passou a ser um componente do próprio capital, uma força produtiva, inserida na lógica de produção capitalista. "Donde as novas formas de financiamento das pesquisas, a submissão delas às exigências do próprio capital e a transformação da universidade numa organização 
ou numa entidade operacional" (CHAUÍ, 2003).

Para Chauí, a universidade se submete a esse sistema de controle porque "está privatizada e a maior parte de suas pesquisas é determinada pelas exigências de mercado, impostas pelos financiadores" (Chauí, 2003, p. 8). É nesse cenário que a sociedade de conhecimento emerge, segundo a filósofa, como princípio legitimador para que os organismos internacionais subsidiem e subvencionem as universidades.

A partir desse ponto, a filósofa nos descreve um quadro desolador: uma forma de docência e pesquisa a serviço de um tempo o tempo da velocidade do capital - que retira a marca essencial do trabalho intelectual e acadêmico, a formação, e submete a pesquisa a critérios quantitativos, baseado em número de artigos publicados, "dos quais dependem a conservação do emprego, a ascensão na carreira e a obtenção de financiamento de pesquisas" (Chauí, 2003). Trata-se de um cenário de insegurança que, segundo a autora, "não gera conhecimento e ação inovadora, e sim medo e paralisia, submissão ao instituído, recusa da crítica, conservadorismo e autoritarismo" (CHAUÍ, 2003, p. 10).

Sem dúvida, o cenário narrado tem seu fundo de verdade e, de fato, a insegurança é uma das faces com as quais o culto ao novo opera. No entanto, não é só disso que se trata. Há em jogo um poderoso aparato discursivo, como vimos no tópico anterior deste ensaio, que opera como contraponto a esse contexto de controle, com base na lógica das infinitas possibilidades de criação dadas pela revolução informacional, junto à promessa de um futuro empreendedor pro- missor. Conforme afirmado por Thrift, o capitalismo tem se tornado um (sério) jogo divertido. Nesse aspecto, as universidades - melhor dito, seus centros tecnológicos - apresentam-se mais como cenário de oportunidades do que de opressão. Histórias de sucesso sobre invenções oriundas de universidades americanas como Harvard, Stanford, Yale, entre outras, têm constantemente alimentado o imaginário de jovens estudantes e professores ao redor do mundo, sendo tema de livros, filmes e palestras motivacionais sobre o real valor do saber no capitalismo informacional.

Tais histórias de sucesso mostram, claramente, como ocorre a relação entre universidade e mercado. Nem se trata de referir aqui as mais famosas delas, a criação de marcas como Google ou Facebook. Com relação a essa última, detenhamo-nos em outra história, publicada no The New York Times: o professor Baker J. Fogg, da Universidade de Stanford, decidiu criar a Classe Facebook, em 2007, solicitando aos seus alunos um dever de casa que consistia na criação de um aplicativo ( $a p p$ ) para o Facebook. A reportagem nos mostra como a simples tarefa de uma disciplina acadêmica transformou-se em um grande negócio: "a Classe Facebook fez disparar carreiras e fortunas de mais de duas dúzias de estudantes e professores. Também ajudou a inaugurar um novo modelo de empreendedorismo que revolucionou o meio tecnológico [pois] encontrou o que se tornou o procedimento operacional para uma nova geração de empresários $\mathrm{e}$ investidores. O fenômeno do app ajudou a liberar o que alguns chamam de nova onda de inovação tecnológica". A reportagem conta como a relação entre a Classe Facebook e o Vale do Silício deu-se desde o início do projeto e como os próprios engenheiros do Facebook frequentaram as sessões universitárias; ao mesmo tempo, ainda segundo a reportagem, os estudantes aprenderam como construir uma empresa e que fazer isso "é muito mais difícil do que criar um $a p p$ ". Ao final, o professor Fogg destaca que o foco de sua matéria era $\mathrm{o}$ desenvolvimento de um aplicativo simples, modelo que hoje enfrenta dificuldades justamente porque o Facebook "dificultou o desenvolvimento de apps de sucesso ao controlar como eles se espalham", mas Fogg apressa-se em dizer que as coisas foram diferentes para aqueles que estavam no lugar certo e na hora certa quando a ideia de sua disciplina foi lançada, quando os aplicativos para Facebook ainda eram uma novidade.

A reportagem acima remete-nos a outro aspecto fundamental no funcionamento do culto ao novo: o investimento no empreendedorismo compreendido, no contexto do capitalismo do conhecimento, com base na noção de capital humano, ou seja, os saberes vivos tais como habilidades, conhecimentos, capacidades que pertencem aos sujeitos. No momento em que o saber se torna "a fonte mais importante da criação de valor, é particularmente o saber vivo o que está na base da inovação, da comunicação e da auto-organização criativa e continuamente renovada". Daí por que o discurso do novo passa a investir nessa forma de saber que "não produz nada materialmente palpável. Ele é, sobretudo na economia de rede, o trabalho do sujeito cuja atividade é produzir a si mesmo" (GORZ, 2005, p. 20, grifo nosso). 
$\mathrm{Na}$ passagem da transformação da noção de trabalho como criador de valor - entendido como produção e dispêndio de energia humana - para o de inovação como valor, a universidade apresenta-se como lócus privilegiado de capital humano na busca de captura e valorização da inovação. Daí por que é nesse contexto que se altera radicalmente a concepção de pesquisa. É o que nos revela, mais uma vez, o estudo de Diaz-Isenrath, ao analisar em detalhes um projeto financiado por uma agência pública de pesquisa no Brasil, mostrando-nos como ele representa um formato de pesquisa induzida, que responde aos imperativos da inovação permanente, que depende de fomento privado, que é conduzido sob a forma de redes/comunidades de pesquisa e que é dominante no mundo acadêmico de hoje. Uma das metas do projeto é "dar um impulso a 'redes colaborativas' e constituir uma plataforma para a experimentação dessas colaborações entre disciplinas acadêmicas e entre centros e grupos de pesquisa em parceria com a indústria". Trata-se, segundo a autora, de uma nova forma de organização do conhecimento, que altera a relação de intervenção do Estado, já que tem como paradigma "as políticas voltadas à interação universidade-empresa, em vigor a partir dos anos 1980 nos Estados Unidos e dos 1990 em países como o Brasil" (DIAZ-ISENRATH, 2008, p. 114). Daí por que, remetendo-se aos escritos de Adrian Mackenzie (2006), a autora conclui que "a integração da pesquisa tecnocientífica pode resultar em lógicas notavelmente próximas às da gestão de conhecimento que, desde meados dos anos 1990, extravasaram os meios empresariais" (DIAZ-ISENRATH, 2008, p. 189).

\section{CONSIDERAÇÕES FINAIS SOBRE UM NOVO REGIME DE CONTROLE}

Para entender o discurso contemporâneo da inovação sob a forma de um culto ao novo e suas consequências no contexto acadêmico, deparei-me com algo muito similar ao que o filósofo Gilles Deleuze definiu como sociedades de controle. Pensando nesse novo regime na década final do século XX, Deleuze previu: "a educação será cada vez menos um meio fechado, distinto do profissional - um outro meio fechado -, mas os dois desaparecerão em favor de uma terrível formação permanente, de um controle contínuo se exercendo sobre o operário-aluno ou o executivo-universitário" (DELEUZE, 1992, p. 216).

Segundo Deleuze, as sociedades de controle sucederam as sociedades disciplinares que vigoraram ao longo do século XX e que tinham como características centrais o confinamento (família, escola, fábrica, hospital, prisão) e uma constante vigilância marcada pelo corpo a corpo. Na verdade, Deleuze afirma que, já após a Segunda Guerra Mundial, era possível perceber que já caminhávamos para deixarmos de ser sociedades disciplinares.

Entre as características enumeradas pelo filósofo para definir as sociedades de controle, destaca-se, para os objetivos deste ensaio, a questão da formação permanente: nas sociedades de controle, nunca se termina nada, seja na empresa ou nas instituições de ensino. "O controle é de curto prazo e de rotação rápida, mas também contínuo e ilimitado, ao passo que a disciplina era de longa duração, infinita e descontínua" (DELEUZE, 1992, p. 224).

De onde viria essa necessidade de formação permanente e por que o controle contínuo? Foi somente associando as características definidoras das sociedades de controle, elencadas por Deleuze, com a minha própria análise sobre o discurso da inovação que entendi a relação entre ambas: a formação e inovação permanentes são partes indissociáveis de um novo estágio do capitalismo, qual seja o capitalismo do conhecimento, que tem no saber a sua principal força produtiva. Nesse cenário, não há mais o monopólio do capitalismo sobre os meios de extração e reprodução do saber operário, como ocorria no taylorismo e no velho management.

As sociedades de controle, segundo Deleuze, seriam resultado de uma inovação tecnológica promovida por novas máquinas. A cada sociedade, diz o filósofo, corresponde um tipo de máquina. As da sociedade de controle seriam os computadores. Mas, como também nos informa Deleuze, não se deve vincular o nascimento das sociedades de controle ao resultado natural da inovação tecnológica, mas a uma profunda mutação do capitalismo que não apenas levou a essa busca por inovação, como também passou a requerer novas formas de agenciamento coletivo.

É interessante a terminologia dada por Deleuze a essa nova etapa das sociedades capitalistas, visto que uma das características centrais desse novo modelo é, justamente, a crise no sistema de controle do trabalho tal qual 
conhecíamos desde o taylorismo. Entendo que o filósofo quis marcar que, evidentemente, o controle não se extingue, mas que passa a operar sob novas bases. E esse é um ponto fundamental para explicar a inflação discursiva em torno dos conceitos de criatividade e inovação nos nossos dias. É nesse sentido que as novas formas de controle passaram a produzir um novo gerencialismo que depende da noção de que o mundo é inconsistente, complexo, paradoxal e confuso. E é nesse cenário que o culto ao novo emerge e opera.

Tomo o discurso contemporâneo em torno da inovação como um desses principais agenciamentos: um poderoso aparato discursivo que coloca a inovação e a gestão do conhecimento sob um mesmo princípio explicativo, sob um novo regime de verdade que não se dissemina apenas no contexto organizacional, mas que se apoia também em um discurso público que passa a priorizar a inovação, com foco em uma pesquisa científica que deveria voltar-se à produção de riqueza. Inovar torna-se, assim, um discurso dominante, sobre o qual não é possível discordar. "Inovar parece remeter a uma espécie de obrigação social, tanto quando se trata da gestão de conhecimento nas empresas quanto da gestão pública da ciência e da tecnologia" (DIAZ-ISENRATH, 2008, p. 82).

O que resultará do modelo-empresa e do modelo-academia nos desdobramentos desse novo regime de controle? Para que futuros apontam? Não tenho, obviamente, respostas para isso, mas acredito que pensar nesse estado de coisas requer mais do que assumir o discurso fácil da inovação que tem interpelado o universo acadêmico tão perversamente, inclusive para que a criação e a invenção possam ser pensadas para além do caráter puramente instrumental da ideia de progresso econômico.

Concordo com o filósofo italiano Giorgio Agamben quando sugere que "crítica significa, sobretudo investigação sobre os limites do conhecimento, sobre aquilo que, precisamente, não é possível nem colocar nem apreender" (AGAMBEN, 2007, p. 9). Creio estarmos vivendo um momento histórico no qual assumir os limites do conhecimento torna-se vital para repensarmos possíveis linhas de fuga ao controle.

É nesse sentido que proponho pensarmos essa inflação discursiva, sob a concepção de uma crítica à ideia de inovação que nos remete a um contexto mais amplo que, como vimos ao longo deste ensaio, está relacionado a um novo "novo espírito do capitalismO" (BOLTANSKY E CHIAPELLO, 2009), a um novo ethos no qual passamos a nos definir como "capital humano" (LÓPEZ-RUIZ, 2007) e, finalmente, a um novo regime de verdade, o "regime de controle" (DELEUZE, 1992). Criatividade e inovação são repetidamente referidas como indicando o caminho viável para a superação de uma velha ordem industrial, burocrática e autoritária, e para o encontro com o admirável mundo novo que tal abertura nos proporcionará. Inovação torna-se uma palavra fetiche que se apresenta como a solução possível para problemas relacionados à educação, saúde, sustentabilidade, segurança, entre outros. Daí a dificuldade de questionarmos esse discurso, e é nesse sentido que nos encontramos diante de uma nova forma de agenciamento coletivo.
A rigor, não se trata de se ser contra a inovação per se, mas de expor, por um lado, um certo mal-estar diante de um discurso que parece tirar-nos a possibilidade de qualquer tipo de questionamento, tamanha a sua positividade; e, por outro, de expor também como, sob a lógica do capital, se assume essa busca da inovação com base em uma nova produção de sentido, quando "O valor do novo se associa menos ao progresso como emancipação social do que à utilidade e à venda para o mercado" (DIAZ-ISENRATH, 2008, p. 84). Trata-se, ao final, de nos perguntarmos de que maneira esse estado de coisas coloca dificuldades para a universidade como instituição social que aspira à universalidade e para o pensamento reflexivo de maneira geral.

A fim de ser coerente com a minha própria crítica, proponho ir na contramão do que se tem definido como artigo acadêmico ou científico, pois acredito que, hoje, a potência da crítica só se faça "num parâmetro descritivo que se desloca ou redefine a ordem das coisas e suas relações, permitindo, a partir daí, estabelecer uma pauta de questões que não podem mais ser resolvidas nos termos habituais e que abre, portanto, a fenda a partir da qual a imaginação crítica pode se mostrar fecunda. Um outro jogo descritivo..." (TELLES, 2007, p. 207).

\section{REFERÊNCIAS}

AGAMBEN, G. A palavra e o fantasma na cultura ocidental. Belo Horizonte: Humanitas-UFMG, 2007.

BOLTANSKI, L; CHIAPELLO, E. O novo espírito do capitalismo. São Paulo: Martins Fontes, 2009. 
BRIN, S; PAGE, L. The anatomy of a large-scale hypertextual Web search engine. Computer Networks and ISDN System, v. 30, n. 1-7, p. 107-117, 1998.

CHAUÍ, M. A universidade pública sob nova perspectiva. Revista Brasileira de Educação, set-dez, n. 24, p. 5-15, 2003.

COURPASSON, D. Managerial strategies of domination: power in soft bureaucracies. Organization Studies, v. 21, n. 1, p. 141-161, 2000.

DELEuZE, G. Conversações. São Paulo: 34, 1992.

DIAZ-ISENRATH, M. C. Máquinas de pesquisa: o estatuto do saber no capitalismo informacional. 2008. Tese de Doutorado em Ciências Sociais, Programa de Pós-Graduação em Ciências Sociais da Universidade de Campinas, Campinas, 2008.

EAGLETON, T. Depois da teoria: um olhar sobre os estudos culturais e o pós-modernismo. Rio de Janeiro: Civilização Brasileira, 2005

FULLER, R. B. Critical path. New York: St. Martins, 1981.

GORZ, A. O imaterial: conhecimento, valor e capital. São Paulo: Annablume, 2005.

HELFT, M. The class that built Apps, and fortunes. The New York Times. New York. Disponivel em : http://www.nytimes. com/2011/05/08/technology/08class. html?_r=2\&pagewanted=all. Acesso 20.12.2011

JAMESON, F. Pós-modernismo: a lógica cultural do capitalismo tardio. São Paulo: Ática, 1996.
LÓPEZ-RUIZ, O. Os executivos das transnacionais e o espírito do capitalismo: capital humano e empreendedorismo como valores sociais. Rio de Janeiro: Azougue, 2007.

MACKENZIE, A. Cutting code: software and sociality. New York: Peter Lang, 2006.

MARTINS, H. The informational transfiguration of the world. Paper series. Investigations in the metaphysic of information. 2005.

ROSE, N. Governing "advanced" liberal democracies. In: BARRY, A; OSBORNE, T; ROSE, N. (Eds) Foucault and political reason: liberalism, neo-liberalism and rationalities of government. Chicago: Chicago University and London UCL, 1996.

SCHUMPETER, J. A teoria do desenvolvimento econômico. São Paulo: Abril Cultural, 1982.

SIEVERS, B. It is new, and has to be done!: socio-analytic thoughts on betrayal and cynicism in organizational transformation. Culture and Organization, v. 13, n. 1, p. 1-21, 2007.

TELLES, V. da S. Transitando na linha de sombra, tecendo as tramas da cidade (anotações inconclusas de uma pesquisa). In: Oliveira, F; Rizek, C. $A$ era da indeterminação. São Paulo: Boitempo, 2007.

THRIFT, N. Knowing capitalism. London: Sage, 2005.

FREITAG, MICHEL. Le naufrage de l'université. Paris: Editions de la Découverte, 1996.

ZIZEK, SLAVOJ. Um dia de cão. Folha de S.Paulo. São Paulo, domingo, 29 de janeiro de 2006. 